be done with more expedition and greater cheapness. The author in his paper certainly advocated abandoning both hammering and cogging. In his paper he said, "Cogging, as it is at present carried on, with its consequent reheating, is a cumbersome, almost an ugly operation, and from the arguments I have endeavoured to adduce, an unnecessary one. How much smarter and cheaper it will be to take the ingots and roll them right off into plates, and I commend this to your earnes attention." Yet in the discussion which followed, Mr. Muirhead said that he did not in his system do without cogging, The point is one of considerable importance, and, Mr. Muirhead's position as the manager of an important steel-producing plant commands for him attention. If the same results can be got from the ingot without cogging and reheating, undoubtedly a great step in advance will have been taken; but the majority of steel-makers-perhaps we might say all, with the exception of Mr. Muirhead-think that cogging or hammering is a necessary though expensive process. Of course, if the author can show that heis right, and the rest of the steel world wrong, he will have performed a signal service to the industry. If we were the owners of steel works, however, we should prefer the experiments to be carried out by other manufacturers. It may be added that what is known as the direct process of rolling is not a new thing, and for Mr. Muirhead to succeed he will have to introduce some entirely fresh element into his procedure.

The last paper read at the meeting was Mr. Clarkson's con. tribution, in which he described his ore sampling machine. It would seem a small matter, at first glance, to sample ore, but it is by no means an easy thing to do. The variations in quality or composition are arbitrarily distributed, and it may easily be that a sample made up from portions from several different positions in the mass to be sampled, may not be a fair representation of the whole. Machines have been before used, by means of which swall portions of a falling mass of ore may be abstracted at regular intervals. It would be difincult to describe this device without the aid of diagrams, but it may be stated that though they appear to work fairly and equitably at first sight, they are in reality partial in their selectiun. Mr. Clarkson has brought a trained mind to bear upon this subject, and has produced a really scientific instrument. The mass of ore is caused to fall in an annular stream, descending into a hopper, which is made to revolve at great speed. By a suitable mechanism small portions of the ore are abstracted at regular intervals, and from the fact that the falling mass takes the form of an annulus in place of a solid stream, the tendency of certain qualities to gather in the middle of the stream is obviated. A small-sized apparatus was shown in the theatre, and the author was able to practically demonstrate the accuracy with which it worked, so far as the exact percentage of the material abstracted from the whole was concerned. The demonstration, it may be said, was perfectly successful. The apparatus has another useful field in distribution of a mass into equal parts, so that by it a number of bottles or boxes can be filled without the tedious process of weighing being gone through, and yet each receptacle will have its due share of the material. The error of the ore separator is less than at present.

This was the last paper read at the meeting, which concluded with the usual votes of thanks.

\section{THEORIES OF THE ORIGIN OF MOUNTAIN IAANGES.}

$\mathrm{N}$ his presidential address, delivered before the American 1 Association for the Advancement of Science this year, Prof. Le Conte dealt with theories of mountain genesis-a subject which lies at the very foundation of theoretical geology. Want of space forbids us printing the address in full, but the most salient points are contained in the extracts from it that are here given.

Prof. Le Conte began by stating those fundamental features of the structure of mountain ranges on which every true theory of their origin must be founded. These features are : (I) Thickness of mountain sediments; (2) coarseness of mountain sediments ; (3) folded structure of mountains ; (4) cleavage structure ; (5) granite or metamorphic axis ; (6) asymmetric form. Another type of mountain, the main characteristics of which

NO. I 249 , vOL. 487 are not included under the above heads, are those only found in the Basin and Plateau regions, and therefore termed the Basin iegion type. In fact, "mountains may be divided into two types, viz. mountains formed by folding of strata, and mountains formed by tilting of crust-blocks. The structure of the one is anticlinal or diclinal, of the other, monoclinal. The Sierra probably belongs to both types. It was formed at the end of the Jurassic as a mountain of the first type, but the whole Sierra block was tilted up on its eastern side without folding at the end of the Tertiary, and it then became also a mountain of the second type. A complete theory must explain this type also; but since from the exceptional character it must be regarded as of subordinate importance, we shall be compelled to confine our discussion to mountains of the usual type."

Before going any further, however, Prof. Le Conte made a digression in orcler to clearly lay down what he meant by theory. After facts have been collected they must be explained, and the explanation, which merely gives the laws of the immediate phenomena in hand, is called the Formal Theory. The next step towards the perfection of knowledge consists in ex plaining the cause of the: e laws, and is termed the Casual or Physical Theory'. 'The following is an illustration of this istinction :-

"All the phenomena of the drift are well explained by the former existence of an ice-sheet moving southward by laws of glacial motion, scoring, polishing, and depositing in its course. This is the formal theory. But still the question remains, What was the cause of the ice-sheet? Was it due to northern elevation, or to Aphelian winter concurring with great eccentricity of the earth's orbit? And if due to northern elevation, what was the cause of that elevation? A perfect theory must answer all these questions."

" . . I wish to keep clear in the mind these two stages of theorising in the case of mountain origin. The formal theory is already well advanced toward a satisfactory condition; the physical theory is still in a very chaotic state. But these two kinds of theories have been often confounded with one another in the popular and even in the scientific mind, and the chaotic state of the latter has been carried over and credited to the former also ; so that many seem to think that the whole subject of mountain origin is yet wholly in the air, and without any solid foundation."

Bearing in mind that " $a$ true formal theory, keeping close to the immediate facts in hand, must pass gradually from necessary inferences from smaller groups to a wider theory which shall explain them all," Prof. Le Conte showed the inferences that could be made from the characteristic features of mountain structure, and he then grouped those inferences, and summed up his views as to the mode of mountain formation as follows:-

\section{Summary Statement of the Formal Theory.}

(I) "Mountain ranges, while in preparation for future birth, were marginal sea-bottoms receiving abundant sediment from an adjacent land-mass and slowly subsiding under the increasing weight. (2) They were at first formed and continued for a time to grow, by lateral pressure crushing and folding the strata together horizontally and swelling them up vertically along a certain line of easiest yielding. (3) That this line of easiest yielding is determined by the hydrothermal softening of the earth's crust along the line of thickest sedimentation. (4) That this line by softening becomes also the line of greatest metamorphism, and by yielding the line of greatest folding and greatest elevation. But (5) when the softening is very great, sometimes the harder lateral strata are jammed in under the crest, giving rise to fan-structure, in which case the most complex foldings may be near but not at the crest. Finally (6) the mountains thus formed will be asymmetric because the sedimentary cylinder-lenses from which they originated were asymmetric."

Several American examples illustrating these views were then given, and it was shown that eruptive phenomena, faults, mineral veins, earthquakes, and other minor phenomena associated with mountains are well explained by them. To quote Prof. Le Conte: "Leaving out the monoclinal type, which seems to belong to a different category, all the phenomena, major and minor, of structure and of occurrences, connected with mountains, are well explained by the theory of lateral pressure acting on lines of thick sediments accumulated on marginal 
sea-bottoms, and softened by invasion of interior heat. This view is therefore satisfactory as far as it goes, and brings order out of the chaos of mountain phenomena. It has successfully directed geological investigation in the past, and will continue to do so in the future.

"But there still remains the question, "What is the cause of the lateral pressure ?' The answer to this question constitutes the physical theory.

- Thus far I suppose there is little difference of opinion. I have only tried to put in clear condensed form what most geologists hold. But henceforward there are the most widely diverse views, and even the wildest speculations. But let us not imagine, on that account, that we have made ro progress in the science of mountain origin. The formal theory already given is really for the geologist by far the most important part of the theory of mountain origin. For I insist that for the geologist, formal theories are usually more important than physical theories of geological phenomena. That slaty cleavage is the result of a mashing of strata by a force at right angles to the cleavage-planes, is of capital importance to the geologist, for it is a guide to all his investigations. To what property of matter this structure is due, is of less importance to him, though of prime importance to the physicist. That the phenomena of the drift is due to the former existence of a moving ice-sheet is the one thing most important to the geologist, guiding all his investigations. Whether this icesheet was caused by geographical or astronomical changes, is a question of wider but of less direct interest to him. So in the case of mountain ranges, the most important part of the theory is their origin by lateral pressure under the conditions given above. The cause of lateral pressure, though still of extreme interest, is certainly of less immediate importance in guiding investigations."

\section{The Contraction Theory.}

"The most obvious view of the cause of lateral pressure refers it to the interior contraction of the earth. This theory is so well known that I will give it only in very brief outline. It assumes that the earth was once an incandescent liquid, and has cooled and solidified to its present condition. At first it cooled most rapidly at the surface, and must have fissured by tension. But there would inevitably come a time when the surface, being substantially cool, and, moreover, receiving heat also from the sun, its temperature would be fixed, or nearly so, while the incandescent interior would be still cooling and contracting. Such has probably been the case ever since the commencement of the recorded history of the earth. The hot interior now cooling and contracting more rapidly than the cool crust, the latter, following down the ever-shrinking nucleus, would be thrust tupon itself by lateral pressure with a force which is simply irresistible. If the crust were ten times, yea, one hundred times more rigid than it is, it must yield. It does yield along the lines of greatest weakness, i.e. along marginal sea-bottoms, as already explained. As a first attempt at a physical theory, it seems reasonahle, and therefore until recently has been generally accepted."

\section{Objections to the Contraction Theory.}

"It is well known that American geologists have taken a very prominent part in the study of mountain structure and mountain origin; so much so, indeed, that the lateral pressure theory in the form given above and interior contraction as its cause, have sometimes been called the 'American theory.' It is also well known that my name, among others-especially Dana's-has been associated with this view. All I claim is to have put the whole subject, especially the formal theory, in a clearer light and more consistent form. ${ }^{1}$ The formal theory I regard as a permanent acquisition. The contraction theory may not be so. It is natural, from my long association with it, that I should be reluctant to give it up. But I am sure that I am willing to do so if a better can be offered. We all dearly love our own intellectual children, especially if born of much labour and thought ; but I am sure that I am willing, like Jephtha of old, to sacrifice, if need be, this my fairest daughter on the sacred altar of Truth. Objections have recently come thick and fast from many directions. Some of these I believe can be removed, but others perhaps cannot in the present condition of science,

I "Theory of the Formation of the Great Features of the Earth's Surface." Am. Journal, vol. iv. p. 345 and 460,1872 ; and also "Structure and Origin of Mountains," vol. xvi. p. 95,1878 .

No. I 249 , Vor 487 and may indeed eventually prove fatal. Time alone can show I state briefly some of these objections."

(I) "Mathematical physicists assure us that on any reasonable premises of initial temperature and rate of cooling of the earth, the amount of lateral thrust produced by interior contraction would be wholly insufficient to account for the enormous foldings (Cam. Phil. Trans. vol. xii. Part 2, December, 1873). Let us admit-surely a large admission-that this is so. But this conclusion rests on the supposition that the whole cause of interior contraction is cooling. There may be other causes of contraction. If cooling be insufficient, our first duty is to look for other causes. Osmund Fisher has thrown out the suggestion (a suggestion, by the way, highly commended by Herschel) that the enormous quantity of water vapour ejected by volcanoes, and the probable cause of eruptions is not meteoric in origin as generally supposed, but is original and constituent water occluded in the interior Magma. (Cam. Phil Trans. vol. xii. Part 2, February, 1875. "Physics of the Earth's Crust," p. 87.) Tschermak has connected this escape of constituent water from the earth with the gaseous explosions of the sun (Geol. Mag. vol. iv. p. 569, 1877). Is it not barely possible that we have in this an additional cause of contraction. more powerfully operative in early times, but still continuing? See the large quantity of water occluded in fused lavas to be 'spit out' in an act of solidification! But much still remains in volcanic glass which by refusion intumesces into lightest froth. Here, then, is a second probable cause of contraction. If these two be still insufficient, we must look for still other causes before rejecting the theory.

(2) "Again, Dutton (An. Four. vol. viii. p. I3, 1874; P(nn. Monthly, May 1876) has shown that in a rigid earth it is impossible that the effects of interior contraction should be concentrated along certain lines so as to form mountain ranges, because this would require a shearing of the crust on the interior. The yielding would be evenly distributed everywhere, and therefore imperceptible anywhere. This is probably true, and therefore a valid objection in the case of an earth equally rigid in every part. But if there be a subcrust layer of liquid or semiliquid or viscous, or even more movable or more unstable matter, either universal or over large areas, as there are many reasons to think, then the objection falls to the ground. For in that case there would be no reason why the effects of general contraction should not be concentrated on weakest lines, as we have supposed.

(3) "But again, it has been objected that the lines of yield. ing to interior contraction ought not to run in definite directions for long distances, but irregularly in all directions. I believe we may find the answer to this objection in the principle of flow of solids under very slow heavy pressure. The flow of the solid earth, under pressure in many directions, might well be conceived as being deflected to the direction of least resistance, i.e. of easiest yielding.

(4) "But again, it will be objected that the amount of circumferential shortening necessary to produce the foldings of some mountains is simply incredible, for it would disarrange the stability of the rotation of the earth itself. According to Claypole, in the formation of the Appalachian range the circum. ference of the earth was shortened 88 miles, and in the formation of the Alps 72 miles. Now this would make a de. crease of diameter of the earth of $\mathbf{2 8}$ miles in the one case, and 23 in the other. This would undoubtedly seriously quicken the rotation and shorten the day. This seems indeed startling at first. But when we remember that the tidal drag is all the time retarding the rotation and lengthening the day, and much more at one time than now, we should not shrink from acceptance of a counteracting cause hastening the rotation and shortening the day, and thus giving stability instead of destroying it. We must not imagine that there would be anything catastrophic in this readjustment of rotation. Mountains are not formed in a day, nor in a thousand years. It requires hundreds of thousands, or even millions of years-if physicists allow us so much.

"The objections thus far brought forward, though serious, are by no means unanswerable. But there is one brought forward very recently which we are not yet fully prepared to answer, and may possibly prove fatal. I refer of course to the level of no strain."

\section{Level of No Strain.}

"Until recently the interior contraction of the earth was considered only roughly and without analysis. It was seen that the 
surface was already cool, and its temperature fixed while the interior was still hot and cooling; and, therefore, that the exterior must be thrust upon itself and be crushed. But the phenomena are really far more complex than at first appears. It is necessary to distinguish between two kinds of contraction to which the interior layers are subjected, viz. radial and circumferential. If there were radial contraction only, then undoubtedly every concentric shell as it descended into smaller space would be crushed together laterally. But there is for all layers, except the surface, also a circumferential contraction, and this would have just the opposite effect, i.e. would tend to stretch instead of crush. Therefore, wherever the decrease of space by descent is greater than the circumferential contraction, there will be crush; and where the circumferential contraction is greater than the decrease of space by descent, there will be tension and tendency to crack. There would be no real cracking, only because incipient cracks would be mashed out, or rather prevented by superincumbent pressure. Where these two are equal to one another, there wil be no strain of any kind. There is a certain depth at which this is the case; it is called the 'level of no strain.' To Mellard Reacle is due the credit of first calling attention to this important principle."

After a diagrammatic representation of this principle, the president continued as follows :-

"Now laborious calculations have been made by Davison, Darwin, and Fisher to determine the depth of this level of no strain. All make it very superficial. Davison, taking an initial temperature of $7000^{\circ} \mathrm{F}$. makes it five miles below the surface. Fisher, on the same data, only two miles, and with an initial tem. perature of 4000 only 0.7 of a mile. It is easy to see that if this be true the amount of lateral thrust must be small indeed.

" Now undoubtedly there is a true principle here which must not hereafter be neglected, but it is almost needless to say that these quantitative results are in the last degree uncertain. The calculations are of course based on certain premises. These are a uniform initial temperature of, say, $7000^{\circ} \mathrm{F}$, a time of cooling, say, 100 or 200 millions of years, and a certain rate of cooling under assumed conditions. The depth of the level of no strain increases with the time, and is still going downward. In a word, in a question so complex, both mathematically and physically, and in which the data are so very uncertain, every cautious geologist, while freely admitting the soundness of the principle, will withhold assent to the conclusions. Huxley has reminded us that the mathematical mill, though a very good mill, cannot make wholesome flour without good wheat. It grinds indifferently whatever is fed to it. It has been known to grind peas ere now. It may be doing so again in this case. Ltt us wait.

"But besides withholding assent, and waiting for more light, I may add that these calculations, of course, go on the supposition that the whole contraction of the earth is due to loss of heat ; bul, as we have already said, it may be due also to loss of constituent water. This would put an entirely different aspect on the subject."

\section{Alternative Physical Theories.}

"I have given the objections to the contraction theory rrankly and, I think, fairly. They are undoubtedly serious. Let us see what has been offered in its place."

\section{Reade's Expansion Theories.}

This, the most prominent among alternative theories, was first brought forward in Mr. Reade's book on "Origin of Mountain Ranges." Although I have carefully read all that Mr. Reade has written on this subject, I find it difficult to get a clear idea of his views. But as I understand it, it is in outline as follows: (I) Accumulation of sediments off shore, and isostatic subsidence of the same. (2) Rise of isogeotherms and beating of the whole mass of sediments and of the underlying crust in proportion to the thickness of the sediments. (3) Expansion of the whole mass in proportion to the rise of temperature. If there were no resistance this expansion would be in all directions (cubic expansion). (4) But since the containing earth will not yield to expansion laterally, this lateral expansion is satisfied by folding, and this in turn produces vertical upswelling. Thus the whole cubic expansion is converted into vertical expansion, which is therefore three times as great as the linear expansion in any one direction. (5) Elevation would of course anyhow be greatest along the line of thickest sediment; but this by itself would not be sufficient to produce a mountain. (6) But farther
- and here the theory is more obscure - there is a concentration of the effects of expansion, along a comparatively narrow line of thickest sediments, by a flow of the hydrothermally plastic or even liquid mass beneath, toward this central line, and then upward through the parted starta, folding these back on either side, and appearing at the crest as the granitic or metamorphic axis. (7) In his latest utterances he seems to adopt the view of Reyer, viz. that the uplifted strata slide back down the slope, producing the enormous crumpling so often found, and exposing a wider area of granite axis. (8) From the same liquid mass which lifts the mountain come also the great fissure-eruptions and the volcanoes.

" $\mathrm{Mr}$. Reade makes many experiments to determine the linear expansion of rocks, and he thinks that these experiments show that when cubic expansion is converted into vertical expansion, and this again concentrated along a line of one-fourth to onefifth the whole breadth of the expanding mass, it would explain the elevation of the highest mountains. But still he seems uncertain if it be enough. In fact, he declares that if it were not for another factor yet unmentioned, he probably would never have brought forward the theory at all.

(9) "This factor is recurrency of the cause and accumulation of the effects. And here the previous obscurity becomes intensified. I have read and re-read this part without being able wholly to understand him. He seems to think that when expansion had produced elevation, the mountain thus formed would not come down again by cooling and contraction; but, on the contrary, would wedge up by normal faulting, and set in its elevated position. Afterward, by new accumulation of beat, another elevation and setting would take place, and the mountain grow higher, and so on indefinitely or until the store of heat is exhausted. Therefore, he characterises his theory as that of 'alternate expansion and contraction,' or, again, as that of 'cumulative recurrent expansion.' Such is a very brief, per haps imperfect, but I hope fair outline of Reade's theory. It seems to me that there are fatal objections to it. These I now state."

\section{Objections to the Theory.}

(I) "The first objection is inadequacy to account for the enormous foldings of mountains, especially when there is no granite axis to fold back the strata. It is true that Mr. Reade makes comparison between his own and the contraction theory in this regard, and seems to show the much greater effectiveness of his own. This may be true if we accept his premises, and compare equal areas in the two cases. But the contraction theory draws from the whole circumference of the earth, and accumulates the ffects on one line, while in Reade's theory the expansion is of course very local.

(2) "But the fatal objection is that brought forward by Davison. It is this : sedimentation cannot, of course, increase the sum of heat in the earth. Therefore the increased heat of the sediments by rise of isogeotherms must be taken from somewhere else. Is it taken from below? Then the radius below must contract as much as the sediments expand, and therefore there will be no elevation. Is it taken from the containing sides? Then the sides must lose as much as the sediments gain, and therefore must contract and make room for the lateral expansion, and therefore there would be no folding and no elevation. I do not see any escape from this objection.

"Thus it seems that Reade's theory cannot be accepted as a substitute. Is there any other?"

\section{Dutton's Isostatic Theory.'}

"Dutton's discussion of isostasy is admirable. but his application of it to the origin of mountains is weak. The outline is as follows :-

"Suppose a bold coast line, powerful erosion and abundant sedimentation. The coast rises by unloading, and the marginal sea-bottom sinks by loading. Now, if isostasy is perfect, there will be no tendency to mountain formation. But suppose a piling up of sediments-but on account of earth rigidity-without immediate compensatory sinking, and a cutting down of coast land without compensalory rising. Then there would be an isostatic slope towards the land, And the accumulated and softened sediments would slide landward, crumpling the strata and swelling them up into a mountain range.

"The fatal objection to this view is that complete isostasy is necessary to renew the conditions of continued sedimentation,

'I Ph.1. Soc. of Washington, Bul.. Vol, xi. pp. 5r-64, 1889 .

NO. [ 249 , VOL. 48 ] 
and therefore to make thick sediments, otherwise the sediments quickly rise to sea-level, and stop the process of sedimentation at that place. But it is precisely a want of complete isostasy which is necessary to make an isostatic slope landward. Dutton refers to Herschel as having suggested a similar cause of strata crumpling and slaty cleavage (Phil. Mag. vol. xii. p. 197, 1856); but the principles involved in the two cases are almost exactly opposite. Herschel supposes sediments to slide down steep natural slopes of sea-bottoms, and therefore sea-ward. Dutton supposed sediments to slide up natural, though down isostatic slopes, landward. Herschel's is a theory of strata-crumpling and slaty cleavage, Dutton's a theory of mountain formation.

"There has been no attempt to carry this idea of Dutton's to quantitative detail. It was probably thrown out as a suggestion in mere despair of any other explanation, for he had already repudiated the contractional theory. But the least reflection is sufficient to convince that such slight want of complete isostatic equilibrium as may sometimes occur, would be utterly inadequate to produce such effects.'

\section{II. Reyer's Gliding Theory.}

"Prof. Reyer has recently put forward certain views fortified by abundant experiments on plastic materials. His idea in brief seems to be this: strata are lifted and finally broken through by uprising fused or semi-fused matters, and these appear above as the granitic axis. As the axis rises, the strata are carried upward on its shoulders, until when the slope is sufficiently steep the strata slide downward, crumpling themselves into complex folds and exposing the granitic axis in width proportioned to the amount of sliding.

"No doubt there is much value in these experiments of Reyer, and possibly such gliding does indeed sometimes take place in mountain strata, and some foldings may be thus accounted for. But the great objections to this view are: (1) that there is no adequate cause given for the granitic uplift, and (2) that it utterly fails to account for the complex foldings of such mountains as the Appalachian and Coast Range, where there is no granite axis at all. Reade, indeed, holds that the Piedmont region is the granite axis of the Appalachian, and that the original strata of the eastern slope are now buried beneath the sea. But American geologists are unanimous in the belief that the shore line of the great interior Palrozoic Sea was but a little east of the Appalachian crest and the sea washed against land of Archran rocks extending eastward from that line."

\section{Conclusion.}

"After this rapid discussion of alternative theories, in which we have found them all untenable, we return again to the contraction theory, not indeed with our old confidence, but with the conviction that it is even yet the best working hypothesis we have."

\section{GEOGRAPHY AT THE BRITISH ASSOCIATION.}

$A S$ in other sections, an absence of sensational papers, and an unusual abundance of good solid work, the outcome of study and research, were the characteristic features in Section E. The president's address was well adapted to his audience; the simplicity of its language, and the vivid descriptions of scenes in the Arctic Basin, with which it abounded, sustained the attention of every listener, and went over the head of none. Perhaps it was better calculated for the extension than the advancement of geographical science, but in many ways advance in geography depends on conditions different from those which determine advance in other sciences. $\mathrm{Mr}$ Seebohm rightly felt that to enforce principles familiar to professed geographers by a picturesque concrete example which no one could misunderstand was better than to record advances in specialised research, which could only appeal to the few geographers whose grasp of the subject equalled his own.

The section met on four days, and, including the presidential address, twenty-seven papers were read ; a large number of members, in addition, took part in various discussions. A feature of the papers was the small number of mere records of travel, and the general striving after some kind of scientific elaboration of the data described. This was in some cases imperfectly done,

1 NATURE, vol. xlvi. p. 224, 1892, and vol. xlvii. p. 81, 1892.

NO. I 249 , VOL. 48 ] but the imperfection was a consequence of the neglect of higher geographical education in this country, and the necessary beat ing out of new paths by independent workers, who, seeing the need for scientific treatment, are not always sure of the right methods to employ.

An inter-sectional discussion with Section $\mathrm{C}$, on the limits between physical geography and geology, had been looked for. ward to with much interest, but proved somewhat disappointing. Few of the speakers addressed themselves to the subject announced, and in the extempore speeches it was evident that, after a faint attempt to come to the point, there was a tendency to fall off on some familiar tack, and repeat irrelevant phrases often said before. In fact, there was no true discitssion, as there was no distinct issue put forward.

Mr. Clements R. Markham, F.R.S., president of the Royal Geographical Society, commenced the proceedings by reading a paper, put logether with consummate skill, in which he argued for the limit of human testimony as the line of demarcation between the domains of physical geography and geology. Thus be established a purely chronological division between phenomena of the same kind, which would fall to the province of one science or the other, according to the date of their manifestation. He concludes-

"Meanwhile, and until better instructed, I should define geology as the study of the condition of the earth and of the changes on its surface during the cycles of ages before the dawn of history; and I should define physical geography as a knowledge of the earth as it is, and of the changes which have taken place on its surface during historical times. These changes, derived from human testimony, explain to us the laws according to which similar changes are now taking place around us.

"The two sciences depend upon each other, and are very closely allied. The geologist finds the same phenomena in the rock formations of the past as the physical geographer discovers on the surface of the earth of the present. Both, for example, have the duty laid upon them of seeling out the agencies which rule in the processes of upheaval and depression. The fold, with its crest and trough, is common to both sciences; and geographers have rejoiced at the announcement of ' a wedding. ring of geology and geography uniting them at once and for ever in indissoluble union."

Mr. W: Topley, F.R.S., who followed, admitted the very close relations of geology and physical geography, but he devoted his attention to establishing the closeness of this relation by bringing forward numerous instances of the dependence of geographical features on geological structure, rather than to defining the limits of the two departments. His contention was that they merged the one into the other, and were not merely contiguous subjects separated by a discoverable line. Mr. E. G. Ravenstein supported Mr. Markham's chronological boundary, and summed up the conclusions of a racy speech in the statement that geology stands to physical geography in precisely the same relationship as history does to political geography. Prof. C. Lapworth, F.R.S., acknowledged the great difficulty of finding any satisfactory dividing line, conterding that the geologist is in many ways absolutely dependent on the physical geographer, and the physical geographer in his turn absolutely dependent on the geologist, the physical geography of the present being indissolubly bound up with the physical geology of the past. Prof. Valentine Ball contended that the relation between geology and geography was similar to that between anatomy and art. Dr. R. D. Roberts, viewing geology as the history of the earth, argued that physical geography was merely the last chapter of that history. Dr. H. R. Mill suggested that a definition between the two departments of knowledge might be found rather in the aspect in which the phenomena of the earth were viewed than in the subject-matter or in chronological order. Physical geography being concerned with the present forms of the earth's surface borrowed from geology an explanation of the observed facts, taking results but not copying methods. Mr. H. Yule Oldham spoke of the unity of geography and of the importance of studying old travels in order to keep a record of recent physical changes. Prof. Bonney, F.R.S., characterised the discussion as waste of tipse and a search after the unattainable, for the words geography and geology contained in themselves all the definition that was required or could be found. Colonel Godwin-Austen and $\mathrm{Mr}$. J. Y. Buchanan, F.R.S., made a few remarks; and Sir Archibald Geikie, who, by the consent of the presidents of Sections $C$ and $E$, occupied the chair, summed up in a judicial manner. He 